\title{
Breastfeeding and complementary feeding associated with body composition in 18- 19 years old adolescents in the 1993 Pelotas Birth Cohort
}

\author{
Silvana Paiva Orlandi ${ }^{*}$, David A. González-Chica², Romina Buffarini ${ }^{1}$ D, Maria Cristina Gonzalez ${ }^{3}$, \\ Ana Maria Baptista Menezes ${ }^{1}$, Fernando C. Barros ${ }^{3}$ and Maria Cecília Formoso Assunção ${ }^{4}$
}

\begin{abstract}
Background: The first years of life are critical for human development, therefore it is important to investigate early factors that may influence the development of body composition later in life. In this study, we aimed to evaluate the association between breastfeeding duration and age of introduction of complementary feeding with body composition at 18-19 years.

Methods: This is a prospective study conducted with adolescents belonging to the 1993 Pelotas Birth Cohort. Duration of breastfeeding, age of introduction of other types of milk and complementary feeding were obtained from a subsample of this cohort periodically monitored during the first year of life. The fat mass (FM) and fat-free mass (FFM) indices were estimated using plethysmography (BOD POD ${ }^{\mathrm{TM}}$ ). Crude and adjusted analyses were stratified by sex using a linear regression model.
\end{abstract}

Results: 1438 adolescents (694 boys and 744 girls) had complete information on exposures and outcomes.. Among men, the mean FMI and FFMI were $4.0 \pm 3.1 \mathrm{~kg} / \mathrm{m}^{2}$ and $19.0 \pm 1.9 \mathrm{~kg} / \mathrm{m}^{2}$; and among women, $8.0 \pm 3.2 \mathrm{~kg} / \mathrm{m}^{2}$ and $15.5 \pm 1.7 \mathrm{~kg} / \mathrm{m}^{2}$, respectively. Neither breastfeeding duration nor age of introduction of complementary foods was associated with mean FMI in both sexes. Mean FFMI was higher among women who were breastfed for three months or more and among men who were breastfed for six months or more. Women who started the complementary feeding after five months of age had lower mean FFMI in adolescence.

Conclusion: The data suggest that only mean FFM in adolescence is associated with early feeding behaviors.

Keywords: Adolescence, Air displacement plethysmography, Breastfeeding, Complementary feeding, Fat mass index, Fat-free mass index, Infancy

\section{Background}

Population-based surveys in Brazil have shown increasing rates of overweight and obesity in all population groups including children and adolescents [1] .

Obesity in adolescents can be assessed using sex and age-specific body mass index (BMI) [2], however, the accuracy of this measure has been questioned because it

\footnotetext{
* Correspondence: silvanaporlandi@gmail.com

${ }^{1}$ Post Graduate Program in Epidemiology, Federal University of Pelotas, Marechal Deodoro 1160, 3rd floor, 96020-220, Pelotas, Pelotas, RS, Brazil

Full list of author information is available at the end of the article
}

does not distinguish between fat mass (FM) and fat-free mass (FFM) [3].

Studies on early origins of diseases have identified early life determinants of excess body fat accumulation $[4,5]$. The first years of life are critical periods of development. It is thus necessary to better understand early life determinants of diseases as they may have a key role in preventing obesity and several other chronic diseases in adolescents and adults [6]. Recent research has established an association between body composition in adulthood and maternal conditions [7], breastfeeding duration [8-10], weight 
gain in the first years of life [11-13], and physical activity levels [14-16].

The association of introduction of complementary foods and body composition in childhood was assessed in some studies [17-19]. Although there is scant evidence regarding introduction of complementary foods and body composition on later periods such adolescence and adulthood based on prospective studies [20]. Furthermore, a systematic review on nutritional determinants of fat-free mass in early adulthood showed that most of the studies on body composition used BMI or doubly indirect methods to assess body composition, such as prediction equations based on indirect methods [20].

The aim of this study was to examine the relationship between total duration of breastfeeding and age of introduction of complementary foods during the first months of life and body composition (FM and FFM assessed by plethysmography) in adolescents 18-19 years of age from the 1993 Pelotas Birth Cohort. We expected that those breastefed for longer time and those who have introduced complementary food later will have higher FFMI.

\section{Methods}

\section{Study subjects}

A prospective longitudinal study was conducted with adolescents belonging to the 1993 Pelotas Birth Cohort. The city of Pelotas is located in southern Brazil and had a population of approximately 328,000 inhabitants in 2010 [21].This cohort consisted of children born in 1993 to mothers living in the urban area. Based on the high percentage of hospital deliveries in the city $(99 \%$ of deliveries), all the five city's hospitals were daily visited by trained fieldwork team members. Of 5265 mothers who delivered in a hospital in 1993, 5249 were included in the study. Since birth, the cohort members were evaluated on several occasions. At 6, 12 and 48 months, the follows-up were carried out in a subsample which comprised all newborns with low birth weight (LBW) $(<2500 \mathrm{~g})$ in addition to a systematic sampling of $20 \%$ of the remaining cohort participants. A detailed description of the Pelotas Birth Cohort methods has been published elsewhere [22].This study included participant with information from five follow-ups: at birth, at ages 6-12and 48 -months, and at 18 -years.

\section{Exposures}

Early independent variables were prospectively collected using semi-structured questions during the first year of life through household interviews with the mothers. For this analysis, we studied total duration of breastfeeding (whether exclusive, predominant (breast milk is the predominant source of nourisment) or partial (breast milk along with formula), age of introduction of milk products (cow's milk or infant formula), and age of introduction of complementary foods (fruits, vegetables and/or other solid or semisolid foods). Exclusive breastfeeding was not assessed due to lack of policies to encourage breastfeeding at that time [23] . Furthermore, the median duration of exclusive breastfeeding in our cohort was 0.1 months [24].. We applied two different breastfeeding variables, one in a dichotomous way (yes/no) and the second one in a polytomous way, categorized according to the duration of breastfeeding as never, $0.01-1.00 ; 1.01-3.00 ; 3.01-6.00$; $6.01-12.00 ;>12.00$ months. The age of introduction of other milk products and complementary foods was categorized as $\leq 1.00 ; 1.01-2.00 ; 2.01-3.00 ; 3.01-4.00 ; 4.01-$ $5.00 ;>5.00$ months.

\section{Outcome measure}

The outcome measure in this study was body composition at age 18-19 years measured using air displacement plethysmography (BODPOD ${ }^{\circ}$, Life Measurement, Inc., Concord, CA, USA). Plethysmography is a safe, fast, and non-invasive method that can be applied in different population groups (obese individuals, children and the elderly). Therefore it has replaced hydrostatic weighing techniques as the method of choice for the measurement of body density [25]. We excluded participants who were unable to undergo this measure due to physical disabilities and limb amputations, in addition to pregnant and potentially pregnant adolescents and those who gave birth in the 3 months preceding the study $(n=68)$.

The dependent variables were the fat mass index (FMI) and fat-free mass index (FFMI). They were adjusted for body size by dividing FM and FFM by height in meters squared $\left(\mathrm{kg} / \mathrm{m}^{2}\right)$ and analyzed as continuous variables. Trained evaluators performed all BODPOD measurements and height measurements taken following a standard protocol using a portable stadiometer accurate to $0.1 \mathrm{~cm}[26,27]$.

\section{Statistical analyses}

In the analysis of this study, cohort participants with complete information on exposures (duration of breastfeeding and age of introduction of other milks and semisolid and solid complementary foods during the first year of life) and outcomes (FMI and FFMI) $(n=1438)$ were included.

For control of potential confounders, the following variables collected in the first follow-up (1993) were studied [20]: maternal age (years); mother's self-reported skin color (white, black/brown, other); per capita household income (divided into quintiles); maternal education (years of complete schooling); pre-pregnancy BMI (weight/height squared using the mother's prepregnancy weight and height self-reported in the perinatal interview included as a numeric variable); smoking during pregnancy (yes/no); gestational age (estimated using the 
last menstrual period; categorized as $<37$ weeks or $\geq 37$ weeks); and LBW (birth weight $<2500 \mathrm{~g}$ ).

The analyses were performed using Stata 12.1 (Stata Corp., College Station, Texas, USA). Data was analysed separately by gender as this is a potential effect modifier in the associations investigated due to differences in body composition between males and females [28]. Categorical variables were described as absolute and relative frequencies, and numerical variables as means and standard deviations (median and interquartile range for asymmetric variables). For crude analyses of exposures and outcomes, we used t-test and ANOVA (heterogeneity of variance or trend depending on the exposure variable) and simple linear regression. We conducted analyses with adjustment for potential confounders for each main exposure studied. Potential confounding variables were included in fully adjusted regression models regardless of their level of statistical significance in the bivariate analysis of the association with the outcome In view of evidence showing that many variables can modify the association between exposure variables and outcome measures [20], we carried out analyses of interactions including the variables maternal nutritional status, skin color, education and household income. We performed all crude and adjusted analyses using sampling weights to take into account the sampling selection procedure. Because the distribution of FMI was nonnormal, analyses used both the original FMI and the natural-log transformed FMI (lnFMI) to allow comparisons of the results.

Given that the present study had a fixed sample size, we retrospectively calculated the minimum detectable difference using the data available with an alpha error of $5 \%$, power of $80 \%$ and FFMI and lnFMI standard deviations. For these estimates, we used the age three months as a cutoff to set the proportion of exposed and nonexposed to the variables breastfeeding and introduction of milk products and complementary foods. Based on these parameters the study could detect mean differences of FFMI between 0.47 and 0.62 in males and 0.39 and 0.53 in females. For lnFMI, the study would have sufficient power to detect differences between $15.6 \%$ and $20.6 \%$ of males and $9.6 \%$ and $14.0 \%$ in females.

The Ethics Committee of the Medicine School of Federal University of Pelotas approved all follow-ups of children from the 1993 Pelotas Birth Cohort. All participants or their guardians provided a signed informed consent at all stages of this study.

\section{Results}

A sample of 4106 adolescents aged 18-19 years were examined between September 2011 and March 2012, accounting for $78.2 \%$ of the original cohort. Table 1 shows that there were no differences regarding gender, maternal age, skin color and household income between participants of the original cohort and those followed up. However, the attrition rate was higher among children of women at extreme education categories (0-4 years and 12 years or more) and those with a previous LBW baby. As for the 1143 participants in the subsample assessed at ages 6 and 12 months $(n=1438)$, the follow-up rate was $79.0 \%$, with no differences for any of the variables mentioned above compared to the initial subsample.

The proportion of males in the sample was $51.7 \%$. They showed higher FFMI and lower FMI compared to females: mean $19.0 \pm 1.9 \mathrm{~kg} / \mathrm{m}^{2}$ and $4.00 \pm 3.1 \mathrm{~kg} / \mathrm{m}^{2}$ in males and $15.5 \pm 1.7 \mathrm{~kg} / \mathrm{m}^{2}$ and $8.00 \pm 3.7 \mathrm{~kg} / \mathrm{m}^{2}$ in females ( $p<0.001$ for both outcome measures). The median FMI and interquartile ranges were $3.0(2.0,5.0)$ in males and $7.1(5.5,9.6)$ in females $(\mathrm{p}<0.001)$.

In males, FMI was higher among those from families with higher household income (mean FMI 4.6 in the highest quintile vs 3.0 in the lowest quintile, $\mathrm{p}<0.001$ ) and was directly associated with pre-pregnancy BMI (mean FMI 6.1 for pre-pregnancy obesity vs 2.8 for prepregnancy underweight, $\mathrm{p}<0.001)$. Pre-pregnancy BMI also showed an association with FFMI (mean FFMI 20.4 for pre-pregnancy obesity vs 17.9 for pre-pregnancy underweight, $p<0.001)$. None of the other variables investigated was associated with either FMI or FFMI in males. Female participants born to smoking mothers showed higher FFMI compared with those born to mothers that did not smoke (15.8 vs. 15.4) and those with LBW had higher FMI compared to normal weight (8.3 vs. 7.5). In addition, those born to mothers with black skin color showed lower FMI and higher FFMI at age 18 compared with white and other color. Similarly to that observed in males, pre-pregnancy BMI was positive associated with both FMI (mean FMI 11.0 for prepregnancy obesity vs 6.1 for pre-pregnancy underweight, $p<0.001$ ) and FFMI (mean FFMI 16.6 for pre-pregnancy obesity vs 14.8 for pre-pregnancy underweight, $\mathrm{p}<$ 0.001) (Additional file 1: Table S1).

Table 2 shows the associations between nutritional variables and FMI and FFMI. In males, the total breastfeeding (in months) was associated with FFMI $(p=0.011)$. In females, those ever breastfed showed higher FFMI than those never breastfed $(p=0.02)$, and those who were given complementary foods at ages 4-5 months showed greater FFMI and FMI. The median (IQR) of FMI according to the exposures is in Additional file 2: Table S2.

Table 3 presents crude and adjusted coefficients of the association of breastfeeding and age of introduction of complementary foods with FMI at age 18-19 years. There were no statistically significant associations between duration of breastfeeding or age of introduction of other milk products and FMI. Regarding the age of introduction of complementary foods, the crude analysis 
Table 1 Comparison between adolescents who were followed-up at 18-y with the original cohort and the sub-sample at 6 and $12-$ months according to sociodemographic and anthropometric variables. 1993 Pelotas Birth Cohort

\begin{tabular}{|c|c|c|c|c|c|}
\hline \multirow[t]{2}{*}{ Variable } & \multirow{2}{*}{$\begin{array}{l}\mathrm{N} \\
\text { original } \\
\text { cohort }\end{array}$} & \multicolumn{2}{|c|}{$\begin{array}{l}\text { Cohort members followed in 2011- } \\
2012\end{array}$} & \multicolumn{2}{|c|}{$\begin{array}{l}\text { Sub-sample cohort members }(n=1438) \text { followed at } 6 \text { and } 12 \text { months and located in } \\
2011-2012\end{array}$} \\
\hline & & $\%$ lost to follow-up ${ }^{a}$ & $p^{\mathrm{b}}$ & $\%$ lost to follow-up ${ }^{c}$ & $p^{d}$ \\
\hline All sample & 5248 & 21.8 & & 21.0 & \\
\hline \multicolumn{6}{|l|}{ Sex } \\
\hline Men & 2603 & 22.6 & 0.149 & 20.4 & 0.627 \\
\hline Women & 2645 & 20.9 & & 21.6 & \\
\hline \multicolumn{6}{|c|}{ Maternal age (years) } \\
\hline$<20$ & 915 & 23.3 & 0.420 & 27.3 & 0.068 \\
\hline $20-34$ & 3756 & 21.6 & & 19.7 & \\
\hline$>35$ & 577 & 20.6 & & 21.2 & \\
\hline \multicolumn{6}{|c|}{ Maternal skin colour ${ }^{e}$} \\
\hline White & 4058 & 22.2 & 0.313 & 21.9 & 0.246 \\
\hline Black & 955 & 20.1 & & 18.8 & \\
\hline Others & 234 & 20.5 & & 14.2 & \\
\hline \multicolumn{6}{|c|}{ Family income at birth (quintiles) ${ }^{e}$} \\
\hline $1^{\circ}$ & 1031 & 24.4 & 0.06 & 24.5 & 0.502 \\
\hline $2^{\circ}$ & 1195 & 21.1 & & 21.1 & \\
\hline $3^{\circ}$ & 889 & 21.0 & & 19.5 & \\
\hline $4^{\circ}$ & 1001 & 18.9 & & 17.9 & \\
\hline $5^{\circ}$ & 1021 & 21.9 & & 20.3 & \\
\hline \multicolumn{6}{|c|}{ Maternal education (years) ${ }^{\mathrm{e}}$} \\
\hline $0-4$ & 1427 & 25.5 & $<0.001$ & 23.4 & 0.572 \\
\hline $5-8$ & 2424 & 19.1 & & 19.8 & \\
\hline $9-11$ & 923 & 20.8 & & 19.9 & \\
\hline$>=12$ & 427 & 26.2 & & 22.9 & \\
\hline \multicolumn{6}{|c|}{ Birth weight (grams) ${ }^{e}$} \\
\hline$<2500$ & 510 & 27.6 & 0.001 & 21.2 & 0.285 \\
\hline$\geq 2500$ & 4722 & 21.0 & & 18.7 & \\
\hline
\end{tabular}

${ }^{\mathrm{a}}$ Number of lost to follow-up in 2012 as a percentage of those evaluated in the original cohort. ${ }^{\mathrm{b}} \mathrm{Chi}$-squared test of the comparison between the cohort members followed-up in 2012 and the original cohort. 'Number of lost to follow-up in 2012 at 6 and 12 months with complete data at 2011-2012 follow-up as a percentage of those evaluated in the sub-sample at 6 and 12 months. ${ }^{d}$ Chi-squared test of the comparison between the cohort members with complete information for analyses at 18 years in relation with the sub-sample followed-up at 6 and 12 months. ${ }^{~}$ Variables with missing data (maximum valor of missing information is $2 \%$ for family income)

showed lower FMI among females who were given complementary foods after the age of five months. However, these differences lost statistical significance after adjustment for confounders. We repeated these analyses using lnFMI, but there were no changes either in the direction of the association or the statistical significance (Additional file 3: Table S3).

On the other hand, FFMI was significantly associated with breastfeeding and age of introduction of complementary foods as shown in Table 4. Regarding the duration of breastfeeding, there was a positive association of breastfeeding on FFMI. Higher FFMI was found in males in both crudes and adjusted analyses, and the breastfeeding for six to 12 months of age showed the greatest mean difference compared to the reference category $(\beta=1.20$;
95\%CI 0.39-2.01), followed by the breastfeeding longer than 12 months. It was also observed a positive effect of breastfeeding on FFMI in females, though it was on the borderline of significance in the crude and adjusted analyses. The same is true when considering the 95\% CI, which is statistically different from the reference category starting from breastfeeding longer than three to six months $(\beta=0.98$; 95\%CI $0.18-1.77)$. This difference remains the same as the duration of breastfeeding increases. When we assessed the association of breastfeeding as a dichotomous variable, the positive effect on FFMI was not evidenced in males (borderline effect in the adjusted analysis) while it became statistically significant in females. Age of introduction of complementary foods was the single variable associated with FFMI; lower FFMI was seen 
Table 2 Descriptive analyses of fat mass index and fat-free mass index at 18 years according to breastfeeding and introduction of complementary feeding during the first year of life, stratified by sex. 1993 Pelotas Birth Cohort $(n=1438)$

\begin{tabular}{|c|c|c|c|c|c|c|}
\hline \multirow[t]{2}{*}{ Independent variables } & \multicolumn{3}{|c|}{$\begin{array}{l}\text { Men }(n=694) \\
\text { Mean }(S D)\end{array}$} & \multicolumn{3}{|c|}{$\begin{array}{l}\text { Women }(n=744) \\
\text { Mean }(S D)\end{array}$} \\
\hline & $\%$ & FMl & FFMI & $\%$ & FMl & FFMl \\
\hline Total breastfeeding (months) & & $0.773^{a}$ & $0.011^{a}$ & & $0.528^{a}$ & $0.063^{a}$ \\
\hline Never & 4.1 & $3.9(3.2)$ & $18.6(1.7)$ & 3.5 & $8.2(3.2)$ & $14.6(1.6)$ \\
\hline $0.01-1.00$ & 17.6 & $4.3(3.5)$ & $19.4(2.1)$ & 15.4 & $8.2(3.9)$ & $15.2(1.7)$ \\
\hline $1.01-3.00$ & 32.0 & $3.9(2.9)$ & $18.9(1.7)$ & 30.6 & $7.9(3.2)$ & $15.5(1.7)$ \\
\hline $3.01-6.00$ & 18.5 & $3.8(2.7)$ & $18.7(1.9)$ & 16.0 & $8.5(4.1)$ & $15.5(1.7)$ \\
\hline $6.01-12.00$ & 12.5 & $4.4(3.1)$ & $19.6(1.9)$ & 12.4 & $9.1(5.2)$ & $15.8(2.0)$ \\
\hline$>12.00$ & 15.3 & $4.3(3.7)$ & $19.4(2.1)$ & 22.1 & $7.9(3.1)$ & $15.7(1.5)$ \\
\hline Breastfeeding & & $0.703^{b}$ & $0.172^{\mathrm{b}}$ & & $0.975^{b}$ & $0.021^{b}$ \\
\hline No & 4.0 & $3.9(3.2)$ & $18.6(1.7)$ & 3.4 & $8.2(3.2)$ & $14.6(1.6)$ \\
\hline Yes & 96.0 & $4.1(3.1)$ & $19.1(1.9)$ & 96.6 & $8.2(3.8)$ & $15.5(1.6)$ \\
\hline Age of introduction of other milks ${ }^{c}$ (months) & & $0.175^{a}$ & $0.187^{\mathrm{a}}$ & & $0.188^{a}$ & $0.624^{a}$ \\
\hline$<=1.00$ & 41.2 & $4.2(3.3)$ & $19.3(2.0)$ & 38.3 & $8.6(3.9)$ & $15.4(1.7)$ \\
\hline $1.01-2.00$ & 24.4 & $3.6(2.4)$ & $18.8(1.9)$ & 25.3 & $7.7(3.1)$ & $15.5(1.7)$ \\
\hline $2.01-3.00$ & 14.0 & $4.1(3.3)$ & $19.0(1.7)$ & 16.3 & $8.4(4.6)$ & $15.4(1.8)$ \\
\hline $3.01-4.00$ & 8.9 & $3.6(2.4)$ & $18.7(1.7)$ & 10.5 & $8.6(4.2)$ & $15.7(1.7)$ \\
\hline $4.01-5.00$ & 6.8 & $4.5(2.7)$ & $19.0(1.9)$ & 4.9 & $8.4(3.5)$ & $15.9(1.6)$ \\
\hline$>5.00$ & 4.7 & $5.0(3.3)$ & $19.6(2.4)$ & 4.8 & $7.3(2.8)$ & $15.2(1.3)$ \\
\hline Age of introduction of other foods ${ }^{d}$ (months) & & $0.887^{\mathrm{a}}$ & $0.280^{a}$ & & $0.031^{\mathrm{a}}$ & $0.013^{a}$ \\
\hline$<=1.00$ & 3.5 & $3.5(3.6)$ & $18.6(1.4)$ & 5.9 & $8.5(2.8)$ & $15.5(1.4)$ \\
\hline $1.01-2.00$ & 16.8 & $4.2(3.3)$ & $19.3(2.3)$ & 15.6 & $8.4(3.9)$ & $15.5(1.8)$ \\
\hline $2.01-3.00$ & 41.2 & $4.0(3.0)$ & $19.0(1.8)$ & 43.1 & $8.1(3.7)$ & $15.5(1.6)$ \\
\hline $3.01-4.00$ & 27.7 & $3.9(2.9)$ & $19.1(1.9)$ & 23.4 & $7.7(3.4)$ & $15.5(1.6)$ \\
\hline $4.01-5.00$ & 8.5 & $4.4(3.1)$ & $19.9(2.1)$ & 9.7 & $9.2(4.7)$ & $15.8(2.0)$ \\
\hline$>5.00$ & 2.4 & $4.6(4.0)$ & $18.1(2.0)$ & 2.3 & $6.6(2.1)$ & $14.5(1.1)$ \\
\hline
\end{tabular}

Abbreviations: $S D$ standard deviation, $F M I$ fat mass index, $F F M I$ fat-free mass index

${ }^{\text {a }}$ Test for Heterogeneity. ${ }^{\text {bT }}$ test. ${ }^{c}$ Cow milk and formula. ${ }^{d}$ Fruits, vegetables and others

among females who were given complementary foods after five months of age $(p=0.036)$.

The interaction analyses including the variables maternal nutritional status, skin color, education, and household income showed no effect modification on the associations.

\section{Discussion}

Studies of early life origins of diseases have suggested that adult health-disease programming can occur as an effect of early exposures during the first years of life [6]. Many studies have investigated the effect of feeding during the first year of life on later life outcomes including a protective effect of breastfeeding against child and adolescent obesity and development of chronic diseases such as hypertension and diabetes mellitus [9]. Strengths of this study include its prospective nature, which permitted the analysis of the effect of breastfeeding and age of introduction of milk products and complementary foods (solid and semisolid foods) on body composition in late adolescence.

Also, body composition was assessed using an accurate assessment method $[25,26]$, with body fat being measured with its compartments (FM and FFM). Another key aspect of this study was the age at which the outcome was evaluated as most studies published to date have assessed body composition in children. The assessment of body composition in late adolescence, a period that is characterized by rapid physical changes with marked effects on adult body composition [13], allows to investigate whether the potential effects of early nutrition are extended beyond childhood.

After adjusting for potential confounders, this study found no statistically significant association between breastfeeding and age of introduction of milk products or complementary foods with FMI at age 18. Victora 
Table 3 Crude and adjusted analyses for fat mass index at 18 years according to breastfeeding and introduction of complementary feeding during the first year of life, stratified by sex. 1993 Pelotas Birth Cohort

\begin{tabular}{|c|c|c|c|c|c|c|c|c|}
\hline \multirow[t]{3}{*}{ Independent variables } & \multicolumn{4}{|l|}{ Male } & \multicolumn{4}{|l|}{ Female } \\
\hline & \multicolumn{2}{|l|}{ Crude } & \multicolumn{2}{|c|}{ Adjusted $^{a}$} & \multicolumn{2}{|l|}{ Crude } & \multicolumn{2}{|c|}{ Adjusted $^{a}$} \\
\hline & $\bar{\beta}$ & $\mathrm{C} 195 \%$ & $B$ & $\mathrm{C} 195 \%$ & $B$ & $\mathrm{C} 195 \%$ & $\bar{\beta}$ & $\mathrm{C} 195 \%$ \\
\hline Total breastfeeding (months) & & $0.773^{a}$ & & $0.707^{a}$ & & $0.528^{a}$ & & $0.171^{\mathrm{a}}$ \\
\hline Never & Ref. (0) & & Ref. (0) & & Ref. (0) & & Ref. (0) & \\
\hline $0.01-1.00$ & 0.45 & $-1.01,1.92$ & 0.90 & $-0.63,2.44$ & 0.06 & $-1.64,1.76$ & -0.14 & $-1,89,1.62$ \\
\hline $1.01-3.00$ & 0.07 & $-1.26,1.40$ & 0.23 & $-1.19,1.65$ & -0.29 & $-1.83,1.24$ & -0.89 & $-2.49,0.73$ \\
\hline $3.01-6.00$ & -0.05 & $-1.42,1.32$ & 0.29 & $-1.18,1.75$ & -0.32 & $-1.40,2.03$ & 0.14 & $-1.61,1.88$ \\
\hline $6.01-12.00$ & 0.51 & $-0.95,1.97$ & 0.55 & $-1.04,2.13$ & 0.91 & $-1.02,2.85$ & 0.60 & $-1.41,2.61$ \\
\hline$>12.00$ & 0.46 & $-1.05,1.98$ & 0.62 & $-0.94,2.19$ & -0.29 & $-1.85,1.26$ & -0.58 & $-2.20,1.04$ \\
\hline Breastfeeding & & $0.703^{b}$ & & $0.471^{b}$ & & $0.975^{\mathrm{a}}$ & & $0.788^{a}$ \\
\hline No & Ref. (0) & & Ref. (0) & & Ref. (0) & & Ref. (0) & Ref. (0) \\
\hline Yes & 0.25 & $-1.03,1.52$ & 0.50 & $-0.86,1.87$ & 0.02 & $-1.46,1.50$ & -0.21 & $-1.78,1.35$ \\
\hline Age of introduction of other milks ${ }^{c}$ (months) & & $0.175^{\mathrm{a}}$ & & $0.371^{\mathrm{a}}$ & & $0.188^{\mathrm{a}}$ & & $0.277^{\mathrm{a}}$ \\
\hline$<=1.00$ & Ref. (0) & & Ref. (0) & & Ref. (0) & & Ref. (0) & \\
\hline $1.01-2.00$ & -0.55 & $-1.24,0.14$ & -0.48 & $-1.17,0.21$ & -0.90 & $-1.77,-0.03$ & -0.77 & $-1.65,0.10$ \\
\hline $2.01-3.00$ & -0.07 & $-1.05,0.90$ & 0.06 & $-0.89,1.01$ & -0.20 & $-1.45,1.06$ & 0.05 & $-1.18,1.28$ \\
\hline $3.01-4.00$ & -0.59 & $-1.49,0.31$ & -0.40 & $-1.30,0.49$ & 0.02 & $-1.37,1.42$ & 0.59 & $-0.75,1.93$ \\
\hline $4.01-5.00$ & 0.31 & $-0.84,1.46$ & 0.09 & $-1.04,1.22$ & -0.18 & $-1.84,1.47$ & 0.07 & $-1.46,1.59$ \\
\hline$>5.00$ & 0.89 & $-0.44,2.22$ & 0.79 & $-0.53,2.11$ & -1.27 & $-2.46,-0.08$ & -0.57 & $-1.60,0.46$ \\
\hline Age of introduction of other foods ${ }^{d}$ (months) & & $0.887^{\mathrm{a}}$ & & $0.561^{\mathrm{a}}$ & & $0.031^{\mathrm{a}}$ & & $0.176^{\mathrm{a}}$ \\
\hline$<=1.00$ & Ref. (0) & & Ref. (0) & & Ref. (0) & & Ref. (0) & \\
\hline $1.01-2.00$ & 0.67 & $-1.33,2.67$ & 0.68 & $-1.28,2.63$ & -0.17 & $-1.60,1.26$ & 0.18 & $-1.10,1.46$ \\
\hline $2.01-3.00$ & 0.50 & $-1.41,2.42$ & 0.16 & $-1.72,2.04$ & -0.43 & $-1.67,0.81$ & -0.17 & $-1.23,0.90$ \\
\hline $3.01-4.00$ & 0.38 & $-1.56,2.32$ & -0.03 & $-1.93,1.88$ & -0.85 & $-2.14,0.45$ & -0.31 & $-1.45,0.83$ \\
\hline $4.01-5.00$ & 0.89 & $-1.19,2.98$ & 0.59 & $-1.41,2.59$ & 0.61 & $-1.16,2.39$ & 0.86 & $-0.68,2.41$ \\
\hline$>5.00$ & 1.10 & $-1.57,3.77$ & 1.04 & $-1.55,3.64$ & -1.99 & $-3.55,-0.43$ & -1.13 & $-2.51,0.24$ \\
\hline
\end{tabular}

Abbreviations: $\beta$ regression coefficient, $\mathrm{Cl} 95 \% 95 \%$ confidence interval. ${ }^{a}$ Test for heterogeneity $\mathrm{T}$ test. ${ }^{\mathrm{b}} \mathrm{T}$ test. ${ }^{\mathrm{c}}$ Cow milk and formula. ${ }^{\mathrm{d}}$ Fruits and vegetables and others

Adjusted for maternal age, maternal skin color, maternal schooling, family income, maternal prepregnancy body mass index, maternal smoking during pregnancy, low birth weight and gestational age

et al. reported similar results while studying participants from another Pelotas birth cohort. They assessed 2250 young adult males 18 years of age and found no association between duration of breastfeeding and adiposity (FM and FMI) measured by bioelectrical impedance [29].

In contrast, one prospective cohort study conducted in the United Kingdom with 536 children born in 1988 found breastfeeding duration to be associated with FM (measured by dual-energy X-ray absorptiometry) after comparing children breastfed for 12 months or more with those who were never breastfed. Those never breastfed had higher FM at age four years $(p=0.002)$. However, it should be noted these are short-term results and also prone to residual confounding and reverse casuality because of observational design [30].
Studies on early introduction of complementary foods and FFM are scarce and inconclusive [20]. In our study, we found associations of both breastfeeding and age of introduction of complementary foods with FFMI.

Although the World Health Organization recommends exclusive breastfeeding for the first six months of life [31], in our study we found that introduction of complementary foods (fruits, vegetables, solid and semi-solid foods) before six months of age was associated with higher FFMI among girls, which has positive implications for health.=. However, caution must be applied as our study did not evaluate the types of complementary foods introduced before six months of age. While there is well-established evidence of short-term benefits of breastfeeding, particularly on the reduction of child morbidity and mortality from infectious diseases [32], long- 
Table 4 Crude and adjusted analyses for fat-free mass index at 18 years according to breastfeeding and introduction of complementary feeding during the first year of life, stratified by sex. 1993 Pelotas Birth Cohort

\begin{tabular}{|c|c|c|c|c|c|c|c|c|}
\hline \multirow[t]{3}{*}{ Independent variables } & \multicolumn{4}{|l|}{ Male } & \multicolumn{4}{|l|}{ Female } \\
\hline & \multicolumn{2}{|l|}{ Crude } & \multicolumn{2}{|c|}{ Adjusted $^{a}$} & \multicolumn{2}{|l|}{ Crude } & \multicolumn{2}{|c|}{ Adjusted $^{a}$} \\
\hline & $\bar{\beta}$ & IC95\% & $\bar{\beta}$ & IC95\% & $\bar{\beta}$ & IC95\% & $\bar{\beta}$ & IC95\% \\
\hline \multicolumn{2}{|l|}{ Total breastfeeding (months) } & $0.011^{a}$ & & $0.006^{a}$ & & $0.063^{a}$ & & $0.079^{a}$ \\
\hline Never & \multicolumn{2}{|l|}{ Ref. (0) } & \multicolumn{2}{|l|}{ Ref. (0) } & \multicolumn{2}{|l|}{ Ref. (0) } & \multicolumn{2}{|l|}{ Ref. (0) } \\
\hline $0.01-1.00$ & 0.79 & $-0.01,1.58$ & 0.92 & $0.08,1.75$ & 0.60 & $-0.26,1.47$ & 0.53 & $-0.26,1.32$ \\
\hline $1.01-3.00$ & 0.31 & $-0.39,1.00$ & 0.37 & $-0.38,1.11$ & 0.89 & $0.06,1.72$ & 0.63 & $-0.13,1.39$ \\
\hline $3.01-6.00$ & 0.04 & $-0.71,0.79$ & 0.29 & $-0.51,1.08$ & 0.95 & $0.08,1.82$ & 0.98 & $0.18,1.77$ \\
\hline $6.01-12.00$ & 0.99 & $0.18,1.79$ & 1.20 & $0.39,2.01$ & 1.44 & $0.27,2.12$ & 1.01 & $0.13,1.89$ \\
\hline$>12.00$ & 0.75 & $-0.06,1.56$ & 0.89 & $0.04,1.73$ & 1.09 & $0.26,1.92$ & 0.90 & $0.13,1.67$ \\
\hline \multicolumn{2}{|l|}{ Breastfeeding } & $0.172^{b}$ & & $0.083^{b}$ & & $0.021^{\mathrm{a}}$ & & $0.035^{a}$ \\
\hline No & Ref. (0) & & \multicolumn{2}{|l|}{ Ref. (0) } & \multicolumn{2}{|l|}{ Ref. (0) } & \multicolumn{2}{|l|}{ Ref. (0) } \\
\hline Yes & 0.46 & $-0.20,1.12$ & 0.63 & $-0.08,1.34$ & 0.94 & $0.14,1.73$ & 0.79 & $0.06,1.52$ \\
\hline \multicolumn{2}{|c|}{ Age of introduction of other milks ${ }^{c}$ (months) } & $0.187^{a}$ & & $0.368^{a}$ & & $0.625^{a}$ & & $0.131^{\mathrm{a}}$ \\
\hline$<=1.00$ & Ref. (0) & & \multicolumn{2}{|l|}{ Ref. (0) } & \multicolumn{2}{|l|}{ Ref. (0) } & \multicolumn{2}{|l|}{ Ref. (0) } \\
\hline $1.01-2.00$ & -0.52 & $-0.98,-0.05$ & -0.40 & $-0.88,0.08$ & 0.07 & $-0.36,0.50$ & 0.24 & $-0.17,0.66$ \\
\hline $2.01-3.00$ & -0.34 & $-0.86,0.19$ & -0.08 & $-0.59,0.44$ & 0.02 & $-0.49,0.54$ & 0.10 & $-0.40,0.60$ \\
\hline $3.01-4.00$ & -0.59 & $-1.20,0.02$ & -0.39 & $-0.95,0.17$ & 0.29 & $-0.26,0.85$ & 0.60 & $0.05,1.15$ \\
\hline $4.01-5.00$ & -0.36 & $-1.15,0.43$ & -0.09 & $-0.84,0.67$ & 0.52 & $-0.23,1.28$ & 0.73 & $0.07,1.39$ \\
\hline$>5.00$ & 0.30 & $-0.84,1.45$ & 0.57 & $-0.55,1.68$ & -0.18 & $-0.78,0.42$ & 0.01 & $-0.53,0.55$ \\
\hline \multicolumn{2}{|c|}{ Age of introduction of other foods ${ }^{d}$ (months) } & $0.280^{\mathrm{a}}$ & & $0.493^{a}$ & & $0.014^{\mathrm{a}}$ & & $0.036^{\mathrm{a}}$ \\
\hline$<=1.00$ & Ref. (0) & & \multicolumn{2}{|l|}{ Ref. (0) } & \multicolumn{2}{|l|}{ Ref. (0) } & \multicolumn{2}{|l|}{ Ref. (0) } \\
\hline $1.01-2.00$ & 0.74 & $-0.12,1.60$ & 0.66 & $-0.14,1.46$ & -0.08 & $-0.79,0.62$ & 0.09 & $-0.69,0.51$ \\
\hline $2.01-3.00$ & 0.44 & $-0.31,1.20$ & 0.36 & $-0.34,1.05$ & -0.03 & $-0.66,0.59$ & -0.11 & $-0.62,0.40$ \\
\hline $3.01-4.00$ & 0.58 & $-0.21,1.37$ & 0.55 & $-0.17,1.28$ & -0.09 & $-0.74,0.56$ & 0.02 & $-0.53,0.56$ \\
\hline $4.01-5.00$ & 0.46 & $-0.49,1.41$ & 0.43 & $-0.41,1.27$ & 0.24 & $-0.59,1.06$ & 0.31 & $-0.36,0.98$ \\
\hline$>5.00$ & -0.43 & $-1.67,0.81$ & -0.13 & $-1.44,1.18$ & -1.07 & $-1.85,-0.28$ & -0.77 & $-1.43,-0.11$ \\
\hline
\end{tabular}

Abbreviations: $\beta$ regression coefficient, $\mathrm{Cl}$ 95\% 95\% confidence interval

Adjusted for maternal age, maternal skin color, maternal schooling, family income, maternal prepregnancy body mass index, maternal smoking during pregnancy, low birth weight and gestational age

${ }^{a}$ Test for heterogeneity. ${ }^{b} \mathrm{~T}$ test. ${ }^{\mathrm{c}} \mathrm{Cow}$ milk and formula. ${ }^{\mathrm{d}}$ Fruits and vegetables and others

term consequences have only recently been studied. Horta et al. conducted a meta-analysis of 71 studies on the impact of breastfeeding and nutritional status at later ages and found a protective effect of breastfeeding against overweight/obesity in later life [9].

In women we found evidence of increased FFMI with a shorter time of exposure of breastfeeding and earlier introduction of complementary foods (semisolid and solid) when compared to men. This gender difference pointing to a female benefit in terms of body composition (e.g. increased FFMI) is biologically plausible since female infants are born with a higher physiological maturity in relation to male [28, 33, 34]. For this reason, we hypothesized that female infants would benefit more of introducing nutrients from semisolid and solid foods at an earlier age in relation to boys.
In a recent meta-analysis Horta et al. verified that the larger the size of the sample of studies evaluating the effect of breastfeeding on adult overweight and/or obesity, the less evident the impact of this association [9]. Although the loss to follow-up was about one-third of the sample in our study, it was not differential by either sociodemographic or birth characteristics.

\section{Conclusion}

In conclusion, this study found significant associations between early nutritional practices and long-term effects on FFMI. It may suggest that both breastfeeding (in male and female infants) and age of introduction of complementary foods (in female infants only) independently affect body composition in young adults. 


\section{Additional files}

Additional file 1: Descriptive analyses of fat mass index and fat-free mass index at 18 years according to sociodemographic and anthropometric variables at birth, stratified by sex. 1993 Pelotas Birth Cohort $(n=$ 1438) (DOCX $31 \mathrm{~kb}$ )

Additional file 2: Descriptive analyses of median (IQR) of fat mass index at 18 years according to breastfeeding and introduction of complementary feeding during the first year of life, stratified by sex. 1993 Pelotas Birth Cohort $(n=1438)$ (DOCX 29 kb)

Additional file 3: Crude and adjusted analyses for the log-transformed fat mass index at 18 years according to breastfeeding and introduction of complementary feeding during the first year of life, stratified by sex. 1993 Pelotas Birth Cohort (DOCX 17 kb)

\section{Abbreviations}

FM: Fat mass; FFM: Fat-free mass; BOD POD ${ }^{\text {TM. }}$ Plethysmography; BMI: Body mass index; FMl: Fat mass index; FFMI: Fat-free mass index; InFMl: Natural-log transformed FMl; LBW: Low birth weight

\section{Acknowledgements}

We are extremely grateful to all colleagues, workers and families who contributed to the 1993 Pelotas Birth Cohorts.

\section{Funding}

This article is based on data from the study "Pelotas Birth Cohort, 1993" conducted by Postgraduate Program in Epidemiology at Universidade Federal de Pelotas with the collaboration of the Brazilian Public Health Association (ABRASCO). From 2004 to 2013, the Wellcome Trust supported the 1993 birth cohort study. The European Union, National Support Program for Centers of Excellence (PRONEX), the Brazilian National Research Council (CNPq), and the Brazilian Ministry of Health supported previous phases of the study.

\section{Availability of data and materials}

The dataset analysed during the current study is available from the corresponding author on reasonable request.

\section{Ethics approval and consent to participate.}

The Ethics Committee of the Medicine School of Federal University of Pelotas approved all follow-ups from the 1993 Pelotas Birth Cohort. All participants or their guardians provided a signed informed consent at all stages of this study.

\section{Authors' contributions}

All the authors are responsible for the reported research, and have made substantial contributions to the conception and design of the study, acquisition and analysis of data. S.P.O, D.G-C and M.C.A designed the research. S.P.O, D.G-C and R.B designed the study's analytic strategy and analyzed data. S.P.O wrote the paper. M.C.G, A.M.M and F.B contributed to the interpretation of data and critically reviewed the manuscript. All authors gave final approval of the version to be published.

\section{Consent for publication}

All participants or their guardians provided a signed informed consent at all stages of this study.

\section{Competing interests}

The authors declare that they have no competing interests.

\section{Publisher's Note}

Springer Nature remains neutral with regard to jurisdictional claims in published maps and institutional affiliations.

\section{Author details}

${ }^{1}$ Post Graduate Program in Epidemiology, Federal University of Pelotas, Marechal Deodoro 1160, 3rd floor, 96020-220, Pelotas, Pelotas, RS, Brazil. ${ }^{2}$ Adelaide Medical School, NHMRC Centre of Research Excellence to Reduce Inequality in Heart Disease, The University of Adelaide, Corner of North
Terrace and George Street Adelaide SA, Adelaide 5000, Australia. ${ }^{3}$ Post Graduate Program in Health and Behavior, Catholic University of Pelotas, Rua Gonçalves Chaves, 373 - sala 411 prédio C, 96015-560. Pelotas, Pelotas, RS, Brazil. ${ }^{4}$ School of Nutrition, Federal University of Pelotas, Rua Gomes Carneiro, $n^{\circ}$ 1. CEP 96010-610. Pelotas, Pelotas, RS, Brazil.

Received: 30 June 2017 Accepted: 14 November 2017

Published online: 01 December 2017

\section{References}

1. Estatística IBdGe. Pesquisa de Orçamentos Familiares 2008-2009: antropometria e estado nutricional de crianças, adolescentes e adultos no Brasil: IBGE; 2010

2. Victora $C G$, Araújo $C L$, de Onis M. Uma nova curva de crescimento para o século XXI Uma nova curva de crescimento para o séculoXXI. 2006.

3. Gonzalez MC, Correia MIT, Heymsfield SB. A requiem for BMI in the clinical setting. Current Opinion in Clinical Nutrition \& Metabolic Care. 2017;20(5):314-21.

4. Kuzawa CW, Hallal PC, Adair L, Bhargava SK, Fall CH, Lee N, et al. Birth weight, postnatal weight gain, and adult body composition in five low and middle income countries. Am J Hum Biol. 2012;24(1):5-13.

5. Wells JC, Chomtho S, Fewtrell MS. Programming of body composition by early growth and nutrition. Proceedings of the nutrition. Society. 2007:66(3): 423-34.

6. Kuh D, Shlomo YB. A life course approach to chronic disease epidemiology: Oxford university press; 2004

7. Lantz H, Bratteby LE, Fors H, Sandhagen B, Sjostrom L, Samuelson G. Body composition in a cohort of Swedish adolescents aged 15, 17 and 20.5 years. Acta Paediatr. 2008;97(12):1691-7. E pub 2008/09/18

8. Cheng S, Volgyi E, Tylavsky FA, Lyytikainen A, Tormakangas T, Xu L, et al. Traitspecific tracking and determinants of body composition: a 7-year follow-up study of pubertal growth in girls. BMC Med. 2009;7:5. Epub 2009/01/28

9. Horta BL, Victora CG. Long-term effects of breastfeeding-a systematic review. 2013.

10. Martin RM, Kramer MS, Patel R, Rifas-Shiman SL, Thompson J, Yang S, Vilchuck K, Bogdanovich N, Hameza M, Tilling K, Oken E. Effects of Promoting Long-term, Exclusive Breastfeeding on Adolescent Adiposity, Blood Pressure, and Growth Trajectories: A Secondary Analysis of a Randomized Clinical Trial. JAMA pediatrics. 2017:e170698-.

11. Larnkjaer A, Schack-Nielsen L, Molgaard C, Ingstrup HK, Holst JJ, Michaelsen KF. Effect of growth in infancy on body composition, insulin resistance, and concentration of appetite hormones in adolescence. Am J Clin Nutr. 2010; 91(6):1675-83. Epub 2010/04/23

12. Leunissen RW, Stijnen T, Hokken-Koelega AC. Influence of birth size on body composition in early adulthood: the programming factors for growth and metabolism (PROGRAM)-study. Clin Endocrinol. 2009;70(2):245-51. Epub 2008/07/12

13. Gonzalez D, Nazmi A, Victora C. Growth from birth to adulthood and abdominal obesity in a Brazilian birth cohort. International journal of obesity (2005). 2010;34(1):195.

14. Ara I, Vicente-Rodriguez G, Perez-Gomez J, Jimenez-Ramirez J, SerranoSanchez JA, Dorado C, et al. Influence of extracurricular sport activities on body composition and physical fitness in boys: a 3-year longitudinal study. Int J Obes. 2006;30(7):1062-71. Epub 2006/06/28

15. Baxter-Jones AD, Eisenmann JC, Mirwald RL, Faulkner RA, Bailey DA. The influence of physical activity on lean mass accrual during adolescence: a longitudinal analysis. J Appl Physiol. 2008;105(2):734-41. Epub 2008/05/10

16. Mundt CA, Baxter-Jones AD, Whiting SJ, Bailey DA, Faulkner RA, Mirwald RL. Relationships of activity and sugar drink intake on fat mass development in youths. Med Sci Sports Exerc. 2006:38(7):1245-54. Epub 2006/07/11

17. Burdette HL, Whitaker RC, Hall WC, Daniels SR. Breastfeeding, introduction of complementary foods, and adiposity at 5 y of age. Am J Clin Nutr. 2006; 83(3):550-8.

18. Caleyachetty A, Krishnaveni GV, Veena SR, Hill J, Karat SC, Fall CH, et al. Breastfeeding duration, age of starting solids and high BMl risk and adiposity in Indian children. Maternal \& child nutrition. 2013;9(2):199-216.

19. Pimpin L, Jebb S, Johnson L, Wardle J, Ambrosini GL. Dietary protein intake is associated with body mass index and weight up to $5 \mathrm{y}$ of age in a prospective cohort of twins. Am J Clin Nutr. 2016:103(2):389-97.

20. Orlandi SP, Schneider BC, Gonzalez MC, González-Chica DA, Assunção MCF. Early nutritional determinants of fat-free mass in early adulthood: a systematic review. Cadernos de saude publica. 2013;29(4):639-53. 
21. Populacional C. Censo Populacional 2010. Instituto Brasileiro de Geografia e Estatística (IBGE)(29 de novembro de 2010) Página visitada em. 2010;11(12):2010.

22. Victora CG, Araujo CL, Menezes AM, Hallal PC, Vieira Mde F, Neutzling MB, et al. Methodological aspects of the 1993 Pelotas (Brazil) birth cohort study. Rev Saude Publica. 2006;40(1):39-46. Epub 2006/01/18

23. Rea MFA. Review of breastfeeding in Brazil and how the country has reached ten months' breastfeeding duration. Cadernos de saude publica. 2003;19:S37-45.

24. González-Chica DA, Gonçalves H, Nazmi A, Santos IS, Barros AJ, Matijasevich $A$, et al. Seasonality of infant feeding practices in three Brazilian birth cohorts. Int J Epidemiol. 2012;41(3):743-52.

25. Ellis KJ. Human body composition: in vivo methods. Physiol Rev. 2000;80(2): 649-80.

26. Fields DA, Goran Ml, McCrory MA. Body-composition assessment via airdisplacement plethysmography in adults and children: a review. Am J Clin Nutr. 2002;75(3):453-67.

27. Lohman TG, Roche AF, Martorell R. Anthropometric standardization reference manual. Illinois: Human kinetics books; 1988.

28. Wells JC. Sexual dimorphism of body composition. Best Pract Res Clin Endocrinol Metab. 2007;21(3):415-30.

29. Victora CG, Barros F, Lima RC, Horta BL, Wells J. Anthropometry and body composition of 18 year old men according to duration of breast feeding: birth cohort study from Brazil. BMJ. 2003:327(7420):901.

30. Robinson SM, Marriott LD, Crozier SR, Harvey NC, Gale CR, Inskip HM, et al. Variations in infant feeding practice are associated with body composition in childhood: a prospective cohort study. The Journal of Clinical Endocrinology \& Metabolism. 2009;94(8):2799-805.

31. World Health Organization and UNICEF. Global strategy for infant and young child feeding. Geneva: World Health Organization; 2003.

32. Victora CG, Barros A. Effect of breastfeeding on infant and child mortality due to infectious diseases in less developed countries: a pooled analysis. Lancet. 2000;355(9202):451.

33. Zeferino A, Barros Filho AA, Bettiol H, Barbieri MA. Acompanhamento do crescimento. J Pediatr. 2003.

34. Wells JC. Natural selection and sex differences in morbidity and mortality in early life. J Theor Biol. 2000;202(1):65-76.

\section{Submit your next manuscript to BioMed Central and we will help you at every step:}

- We accept pre-submission inquiries

- Our selector tool helps you to find the most relevant journal

- We provide round the clock customer support

- Convenient online submission

- Thorough peer review

- Inclusion in PubMed and all major indexing services

- Maximum visibility for your research

Submit your manuscript at www.biomedcentral.com/submit 